\title{
ESTUDOS DA ELETRODEPOSIÇÃO DE METAIS EM REGIME DE SUBTENSÃO
}

Mauro C. Santos, Sergio A. S. Machado* e Luis A. Avaca

Instituto de Química de São Carlos - Universidade de São Paulo - CP 780, 13560 - 970 São Carlos - SP

Lucia H. Mascaro

Departamento de Química - Centro Politécnico - Universidade Federal do Paraná - Jardim das Américas - 81531-900 Curitiba - PR

Recebido em 2/7/99; aceito em 24/9/99

\begin{abstract}
STUDIES OF THE UNDERPOTENTIAL DEPOSITION OF METALS. This work reviews recent studies of underpotential deposition (UPD) of several metals on Pt and Au substrates performed in the Grupo de Materiais Eletroquímicos e Métodos Eletroanalíticos (IQSC - USP, São Carlos). The UPD $\mathrm{Cu}, \mathrm{Cd}$ and $\mathrm{Pb}$ on Pt were analysed in terms of their influence in the oxygen evolution reaction. Partial blockage of surface active sites, promoted by $\mathrm{Pb}$ ad-atoms, resulted in a change from water to hydrogen peroxide as the final product. The Ag UPD on Pt and Au substrates was also discussed in this work. A detailed model of charge calculation for Ag monolayer was developed and confirmed by the rotating ring-disk data. The partial charge transfer in UPD studies was analysed in the Cd/ $\mathrm{Pt}$ and $\mathrm{Cd} / \mathrm{Au}$ systems and a value of 0.5 was found for the adsorption electrovalence of Cd ad-ions. The Sn/Pt UPD systems were studied from the point of view of the valences of metallic ions in solution. The deposition from $\operatorname{Sn}(\mathrm{IV})$ generates a full monolayer with a maximum occupation of approximately $40 \%$ of the surface active sites $\left(340 \mu \mathrm{C} \mathrm{cm}^{-2}\right)$ plus $105 \mu \mathrm{C} \mathrm{cm}$ of $\mathrm{H}_{\text {ads }}$ (half monolayer). Changing the metallic ion for $\mathrm{Sn}(\mathrm{II})$, it was possible to deposit a full monolayer $\left(210 \mu \mathrm{C} \mathrm{cm}^{-}\right.$ $\left.{ }^{2}\right)$ without any detectable $H_{\text {ads. }}$. Finally, the effect of anions was discussed in the $\mathrm{Zn} / \mathrm{Pt}$ and $\mathrm{Zn} / \mathrm{Au}$ systems. Here, the hydrogen evolution reaction (her) and the hydrogen adsorption/desorption were used in order to investigate the maximum coverage of the surface with $\mathrm{Zn}$ ad-atoms. The full monolayer, characterised by the complete absence of $\mathrm{H}_{\text {ads }}$, was achieved only in $0.5 \mathrm{M}$ HF solutions.
\end{abstract}

Keywords: underpotential deposition; ad-atoms; adsorption.

\section{INTRODUÇÃO}

Em eletrocatálise, o conceito de sítio ativo na superfície eletródica é de fundamental importância. O número e a disposição geométrica dos centros de adsorção normalmente determinam o mecanismo da reação em estudo, assim como a natureza do produto formado ${ }^{1}$. Um exemplo da influência da natureza do sítio ativo no mecanismo da reação pode ser encontrado na reação de redução do oxigênio. Sobre superfícies que disponham de dois centros de adsorção vizinhos separados por uma determinada distância, onde a molécula de oxigênio possa se adsorver numa estrutura tipo ponte, a reação ocorre com a transferência de quatro elétrons, resultando em água como o produto formado. Isto ocorre por exemplo sobre $\mathrm{Pt}^{2,3}$. Por outro lado, a falta da distância ideal entre os centros de adsorção leva, normalmente a adsorção da molécula a ocorrer da forma linear, sobre apenas um sítio, e a reação resulta na formação de água oxigenada, com a transferência de apenas dois elétrons, como ocorre sobre $\mathrm{Au}^{4}$. Desta forma, a alteração, de maneira controlada, do número e da distância entre os centros de adsorção na superfície eletródica possibilita o planejamento de substratos catalíticos para determinadas reações de interesse.

Uma das maneiras mais adequadas de se obter a modificação controlada da natureza dos sítios ativos da superfície de um eletrodo é pela deposição em subtensão de metais. A deposição em subtensão de átomos metálicos, M, em um substrato diferente, $\mathrm{S}$, tem atraído um enorme interesse nas últimas décadas $^{5-9}$. Basicamente, o fenômeno da deposição em regime de subtensão está relacionado com a possibilidade de se depositar até uma monocamada de um dado metal, M, em potenciais

e-mail: sasmach@iqsc.sc.usp.br mais positivos do que aquele relacionado com o equilíbrio $\mathrm{M}^{\mathrm{z}+}$ M (potencial de Nernst). Esta aparente violação da lei de Nernst tem como explicação o excesso de energia da ligação entre o átomo adsorvido (frequentemente chamado de ad-átomo) e o substrato $\left(\mathrm{S}-\mathrm{M}_{\mathrm{ads}}\right)$ em relação à energia de ligação entre um átomo depositado em uma superfície do próprio metal (M$\left.\mathrm{M}_{\mathrm{ads}}\right)^{10}$ :

$\mathrm{S}-\mathrm{M}_{\mathrm{ads}}>\mathrm{M}-\mathrm{M}_{\mathrm{ads}}$

O deslocamento positivo do pico de deposição em subtensão, $\Delta \mathrm{E}$, pode ser desde alguns milivolts até algumas centenas de milivolts, dependendo da intensidade das interações entre o adátomo e o substrato.

A deposição em subtensão pode ser descrita por uma equação eletroquímica do tipo ${ }^{11}$ :

$\mathrm{vS}-\mathrm{OH}_{2}+\mathrm{M}^{\mathrm{Z}+}(\mathrm{aq})+\lambda \mathrm{e} \rightleftharpoons \mathrm{Sv}-\mathrm{M}_{\mathrm{ads}}{ }^{(\mathrm{z}-\lambda)+} \mathrm{vH}_{2} \mathrm{O}(\mathrm{aq})$

onde $\lambda$ é o coeficiente de transferência parcial de carga, introduzido por Lorenz e Salié ${ }^{12}$ e $v$ o número estequiométrico. $\mathrm{O}$ primeiro parâmetro leva em consideração o fato de que a transferência de carga ocorre em uma etapa elementar não integral durante a eletrossorção. A carga parcial dos ad-átomos é normalmente muito pequena e não pode ser medida experimentalmente. Seguindo um formalismo Nernstiano, o potencial de equilíbrio para o pico na região de subtensão $\left(E_{M C}\right)$ pode ser definido por $^{13}$ :

$\mathrm{E}_{\mathrm{MC}}=\mathrm{E}_{\mathrm{MC}}^{0}+\frac{\mathrm{RT}}{\gamma \mathrm{F}} \ln \left(\frac{\mathrm{a}_{\mathrm{M}^{\mathrm{Z}+}}}{\mathrm{a}_{\mathrm{MC}}}\right)$

onde $\mathrm{a}_{\mathrm{Mz}+}$ é a atividade do metal no eletrólito, $\mathrm{a}_{\mathrm{MC}}$ a atividade 
do metal adsorvido com um grau de recobrimento variando entre 0 e 1 e $\gamma$ a valência de eletrossorção do metal adsorvido.

Além da possibilidade de se alterar a distribuição dos sítios ativos na superfície de um eletrocatalisador, a deposição em subtensão de $\mathrm{Zn}$ sobre substratos como $\mathrm{Ni}$ ou Co tem sido utilizada para explicar a eletrodeposição anômala de $\mathrm{Zn}$ em ligas Ni-Zn ou Co-Zn ${ }^{14-17}$. Nestas deposições de grande interesse comercial, o metal menos nobre $(\mathrm{Zn})$ deposita-se preferencialmente ao $\mathrm{Ni}$ ou ao Co. Assim, um recobrimento inicial da superfície mais nobre com uma monocamada de $\mathrm{Zn}$ depositada em subtensão, deveria favorecer a deposição deste último metal, levando à situação anômala observada.

\section{TÉCNICAS ELETROQUÍMICAS UTILIZADAS NOS ESTUDOS DA DRS}

Diversas técnicas experimentais, eletroquímicas ou não, tem sido utilizadas para o estudo da deposição em subtensão de um número considerável de metais, sobre diversos substratos. Inicialmente, a cronopotenciometria foi a técnica experimental empregada, por exemplo, na busca da dependência do tempo de redissolução de monocamadas de $\mathrm{Pb}$ sobre $\mathrm{Au}^{18}$ ou de $\mathrm{Ag}$, $\mathrm{Pb}$ e $\mathrm{Cu}$ sobre $\mathrm{Pt}^{19}$. Os transientes de corrente obtidos apresentavam freqüentemente várias ondas para a redissolução de um mesmo metal, fenômeno este que foi associado às interações dos ad-átomos com diferentes tipos de sítios ativos sobre o substrato. Bowles ${ }^{20}$, também utilizando a cronopotenciometria, estudou a substituição dos ad-átomos de hidrogênio por adátomos de $\mathrm{Cu}^{20}$ sobre $\mathrm{Pt}$ policristalina. Este autor utilizou curvas de pseudo-capacidade diferencial para discutir o comportamento eletroquímico deste sistema. Estas curvas mostraram claramente que, para pequenas quantidades de cobre em solução, a deposição ocorria em potenciais mais positivos que o de equilíbrio e que, ao se aumentar significativamente a concentração dos íons $\mathrm{Cu}^{2+}$, observava-se a deposição Nernstiana.

Uma das técnicas mais ricas em possibilidades dentre as utilizadas nesta área é a voltametria cíclica. Através da variação do potencial a uma velocidade controlada, observa-se a resposta em forma de variação de corrente, para qualquer reação que ocorra na superfície eletródica. Nesta técnica, a quantidade de metal depositada a um certo potencial pode ser obtida como uma carga equivalente através da varredura anódica de potenciais e da integração da corrente de oxidação causada pela dessorção do depósito. A voltametria cíclica fornece informações sobre as isotermas de adsorção, mesmo em baixos recobrimentos, devido à grande sensibilidade das medidas de corrente. Além disto, variando-se a velocidade de varredura em um grande intervalo, podem ser obtidas informações cinéticas do comportamento da deposição em subtensão e dos passos determinantes da velocidade das reações envolvidas. Desta maneira, este método fornece rapidamente dados termodinâmicos e cinéticos básicos, sendo bastante adequado para a detecção de pequenas quantidades de espécies reativas. Assim, não é surpresa a grande quantidade de trabalhos publicados nesta área utilizando como técnica experimental eletroquímica básica a voltametria cíclica ${ }^{21-29}$.

No entanto, Swathirajan et al. ${ }^{13}$ contestam o uso de técnicas eletroquímicas que utilizam apenas um eletrodo de trabalho para este tipo de estudo, pois postulam que o conjunto de dados resultantes não é suficiente para separar os fluxos de massa e de carga no eletrodo. Isto é necessário para se definir duas variáveis interligadas e que não são facilmente separáveis, a saber, o número de elétrons transferidos (ou a valência de eletrossorção) e o número de sítios ativos ocupados na adsorção de cada ad-átomo. Uma possibilidade muito interessante para a separação destes parâmetros consiste na utilização do eletrodo rotatório de disco-anel ${ }^{30}$. Nesta técnica, utilizam-se quatro eletrodos, sendo dois de trabalho mais o de referência e o auxiliar. Os eletrodos de trabalho são: o eletrodo de disco, onde a reação de interesse se desenvolve e o eletrodo de anel, que normalmente serve como eletrodo coletor das espécies intermediárias formadas na reação do disco. Alternativamente, o eletrodo de anel pode ser utilizado para quantificar o processo de dissolução anódica de espécies inicialmente depositadas no eletrodo de disco. O eletrodo de disco-anel é mantido a uma velocidade de rotação constante, durante cada experimento, para assegurar que as espécies formadas no disco cheguem ao anel através da difusão convectiva. Na Figura 1 se apresenta um esquema do eletrodo rotatório de disco-anel. Aqui, um parâmetro de fundamental importância, além das respectivas áreas, é o fator de coleção $(\mathrm{N})$, ou seja, a fração do total de espécies geradas no eletrodo de disco que atinge o anel (e é coletada) em um dado experimento. Este fator é dado por uma relação entre os raios do disco, do anel e a distância entre ambos e pode ser obtido da equação ${ }^{31}$ :

$\mathrm{N}=1-\mathrm{F}\left(\frac{\alpha}{\beta}\right)+\beta^{2 / 3}[1-\mathrm{F}(\alpha)]-(1+\alpha+\beta)^{2 / 3}$

onde:

$\alpha=\left(\frac{r_{2}}{r_{1}}\right)^{3}-1, \beta=\left(\frac{r_{3}}{r_{1}}\right)^{3}-\left(\frac{r_{2}}{r_{1}}\right)^{3}$

e

$\mathrm{F}(\theta) \equiv \frac{3^{1 / 2}}{4 \pi} \ln \frac{\left(1+\theta^{1 / 3}\right)}{1+\theta}+\frac{3}{2 \pi} \arctan \left(\frac{2 \theta^{1 / 3}-1}{3^{1 / 2}}\right)+\frac{1}{4}$

nestas equações, $r_{1}$ é o raio do eletrodo de disco, $r_{2}$ o raio interno do eletrodo de anel e $r_{3}$ o raio externo. Como estas equações são bastante difíceis de se manipular, na prática costuma-se determinar o fator de coleção como a razão entre as correntes limites de difusão do disco e do anel, para um processo eletródico bem conhecido, como o par redox $\mathrm{Fe}(\mathrm{II}) / \mathrm{Fe}(\mathrm{III})^{3}$.

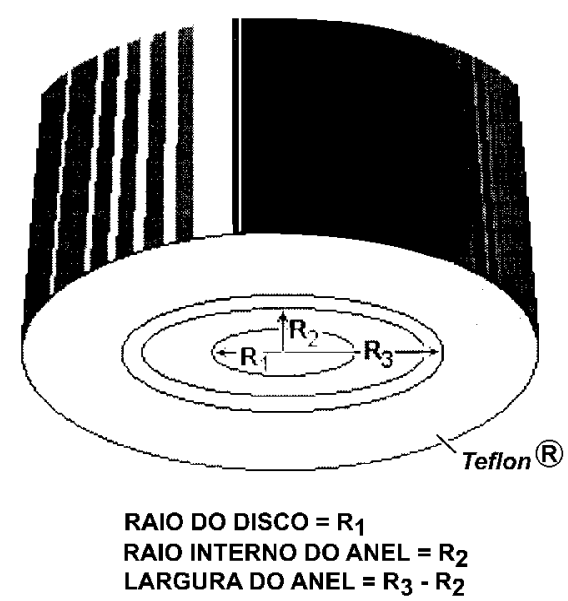

Figura 1. Representação esquemática da ponta de um eletrodo rotatório de disco-anel.

Para a separação entre os fluxos de carga e massa, em experimentos de DRS, utiliza-se o experimento conhecido como coleção. Nele, o anel é polarizado a um potencial suficientemente negativo, para promover inicialmente a deposição maciça do metal em estudo. Assim, após um tempo de deposição adequado, o eletrodo de anel torna-se totalmente revestido com 
aquele metal e a deposição, no anel, passa então a ser governada pela lei de Nernst (deposição nernstiana):

$$
\mathrm{E}=\mathrm{E}^{0}+\frac{\mathrm{RT}}{\mathrm{nF}} \log \frac{\mathrm{a}_{\mathrm{Me}^{\mathrm{Z}+}}}{\mathrm{a}_{\mathrm{Me}}}
$$

onde n é o número de elétrons transferidos. Desta forma, a corrente de deposição se torna constante e dependente apenas da concentração do íon metálico em solução e da velocidade de rotação do eletrodo. Além disto, cada íon que atinge o anel e se descarrega totalmente sobre o depósito inicial, passa a ocupar um sítio ativo da superfície do anel. A seguir, deposita-se, a um dado potencial, uma monocamada completa do metal em estudo sobre o eletrodo de disco. Durante esta deposição, a corrente do anel diminui devido ao esgotamento de íons metálicos na interface. Após o término da deposição no disco, a corrente do anel retorna ao seu valor inicial, indicando a homogeneização do perfil de concentração. No próximo passo, executa-se uma varredura anódica de potenciais no disco, visando ocasionar a dissolução total da monocamada obtida sobre este eletrodo. Isto causa um aumento na concentração de íons metálicos na interface e, consequentemente, na corrente do anel. Após a dissolução da monocamada, a concentração iônica na interface e a corrente do anel voltam ao seus valores originais.

Com a área sob a curva de variação de corrente do anel, a área real do eletrodo de disco e o fator de coleção do sistema, pode-se calcular a carga da monocamada de metal dissolvida da superfície do eletrodo de disco. As vantagens da utilização desta metodologia estão relacionadas com a eliminação das interferências da superfície na deposição. Aqui não se observa mais a interação substrato - ad-átomo, assim como a discussão sobre o número de sítios ocupados e a valência de eletrossorção não se aplica mais. Além disto, a resposta relacionada à superfície do eletrodo de disco, como a adsorção/desorção de hidrogênio, a formação/redução do óxido superficial e as correntes capacitivas devidas à dupla camada elétrica, não interferem no cálculo desta carga. Desta forma, a utilização desta técnica permite elucidar, com precisão e segurança, as cargas envolvidas nos processos de deposição em regime de subtensão, inclusive o recobrimento máximo possível de se atingir durante a DRS de metais em substratos distintos.

\section{ESTUDOS DE DEPOSIÇÃO EM REGIME DE SUBTENSÃO (DRS)}

O Grupo de Materiais Eletroquímicos e Métodos Eletroanalíticos (GMEME) têm realizado diversos estudos envolvendo a deposição em regime de subtensão (DRS) de diferentes metais, como por exemplo $\mathrm{Cu}, \mathrm{Pb}, \mathrm{Ag}, \mathrm{Cd}$ e $\mathrm{Zn}$, sobre substratos policristalinos de Au e Pt. Estes estudos visaram determinar certos parâmetros importantes da deposição dos ad-átomos tais como: o número de elétrons transferidos, o número de sítios ativos da superfície ocupados por cada átomo depositado, a influência do processo de deposição sobre reações superficiais do substrato, neste caso sobre a reação de redução de oxigênio, o efeito da co-adsorção de ânions na deposição e a adsorção com transferência parcial de carga, entre outras. A seguir será feita uma análise resumida de cada estudo com suas características peculiares e possíveis aplicações.

Como estes estudos foram feitos, em sua quase totalidade, em meio ácido, os potenciais citados são relativos ao eletrodo de referência de hidrogênio na mesma solução de trabalho.

\section{Influência da DRS de diversos metais na reação de redução de oxigênio.}

Conforme discutido na Introdução deste trabalho, a deposição de átomos metálicos em regime de subtensão sobre a superfície de Pt policristalina pode afetar, de maneira marcante, a reação de redução de oxigênio (rro). Nesta área, a DRS de $\mathrm{Cu}, \mathrm{Pb}$ e $\mathrm{Cd}$ foi estudada sobre Pt policristalina em meio de $\mathrm{H}_{2} \mathrm{SO}_{4}$ 0,5 M, visando determinar o efeito do recobrimento parcial com ad-átomos na $\mathrm{rro}^{32-34}$. Estes estudos foram feitos utilizando-se o eletrodo rotatório de disco-anel em dois distintos tipos de aplicação. Inicialmente, a técnica de coleção foi empregada visando-se obter as cargas de dissolução de frações da monocamada (submonocamadas) dos metais em estudo, sem a interferência da oxidação superficial do substrato, da reação de adsorção/dessorção de hidrogênio, etc.. Este estudo foi executado com a metodologia descrita na seção anterior. Alguns importantes resultados obtidos demonstraram que o $\mathrm{Cu}^{32}$ forma uma monocamada completa com carga de dessorção de $420 \mu \mathrm{C}$ $\mathrm{cm}^{-2}$. Como já é muito conhecido ${ }^{3,9}$, a oxidação de uma monocamada completa de hidrogênio adsorvido sobre Pt produz uma carga de $210 \mu \mathrm{C} \mathrm{cm}^{-2}$, com cada ad-átomo de hidrogênio ocupando um único sítio ativo da superfície da Pt e sofrendo uma transferência de apenas um elétron. Por comparação pode-se dizer que a ocupação completa dos sítios ativos da superfície da $\mathrm{Pt}$ envolve uma carga de $210 \mu \mathrm{C} \mathrm{cm}^{-2}$ por elétron e por sítio

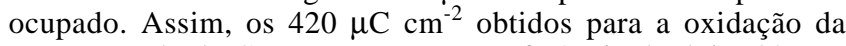
monocamada de $\mathrm{Cu}_{\text {ads }}$ sugerem a transferência de dois elétrons por ad-átomo e o bloqueio de todos os sítios ativos da superfície. No caso do $\mathrm{Cd}^{33}$, determinou-se um recobrimento máximo de $319 \mu \mathrm{C} \mathrm{cm}^{-2}$ e uma valência de eletrossorção de 0.45 . Neste caso, foi observada pela primeira vez uma transferência parcial de carga. Corrigindo-se os valores da densidade de carga pelo número efetivo de elétrons transferidos encontra-se o recobrimento máximo com os ad-átomos. Assim, foi possível encontrar a deposição epitaxial de uma monocamada completa de $\mathrm{Cd}^{0.5+}$ sobre Pt. Já para o $\mathrm{Pb}^{34}$, encontrou-se uma carga de dessorção da monocamada de apenas $88 \mu \mathrm{C} \mathrm{cm}^{-2}$, o que justifica um recobrimento máximo de apenas $42 \%$ dos sítios ativos da superfície. Este baixo recobrimento foi associado com a diferença entre os raios atômicos do $\mathrm{Pb}$ e da $\mathrm{Pt}\left(\mathrm{r}_{\mathrm{Pb}} / \mathrm{r}_{\mathrm{Pt}}=1,3\right)$. Isto causa um empacotamento aberto dos ad-átomos de $\mathrm{Pb}$, com muitos sítios ativos da superfície ficando sem recobrimento. Após esta discussão inicial sobre os mecanismos de DRS, utilizou-se a técnica do eletrodo rotatório de disco-anel para o estudo do mecanismo da rro, sobre Pt modificada pelas DRS destes três metais. Para isto, o eletrodo de anel foi polarizado em 1,20 V visando oxidar o $\mathrm{H}_{2} \mathrm{O}_{2}$ formado no disco e coletado no anel. Assim, o anel serviu como detetor de um importante intermediário da reação. A Figura 2 mostra os resultados obtidos para a rro sobre $\mathrm{Pt}$ modificada por $\mathrm{Cu}(\mathrm{A}), \mathrm{Cd}(\mathrm{B})$ e $\mathrm{Pb}$ (C) em $\mathrm{H}_{2} \mathrm{SO}_{4} \quad 0,5 \mathrm{M}$, para diversas concentrações dos íons metálicos em solução. Aqui, a velocidade de rotação do eletrodo foi mantida constante em $1400 \mathrm{rpm}$, com o potencial do disco sendo varrido entre 1,0 e $0,0 \mathrm{~V}$ a $30 \mathrm{mV} \mathrm{s}^{-1}$ enquanto o do anel foi mantido constante em $1,20 \mathrm{~V}$. No caso do $\mathrm{Cu}$ e do $\mathrm{Cd}$, observa-se uma inibição na corrente difusional do disco com a incursão de potenciais para valores mais negativos. Esta inibição está associada com uma mudança no mecanismo da reação, com o produto final mudando de água para $\mathrm{H}_{2} \mathrm{O}_{2}$ (uma diminuição de quatro para dois elétrons transferidos). Isto está evidenciado pelo aumento da corrente no anel, que tem um potencial adequado para oxidar a água oxigenada formada no disco e que difunde até ele, sendo então coletada. Esta mudança de mecanismo é ocasionada pelo bloqueio pelos ad-átomos dos pares de sítios ativos vizinhos, necessários para a molécula de $\mathrm{O}_{2}$ se adsorver na forma de "ponte' ${ }^{32}$. Entretanto, com o aumento do recobrimento superficial do disco com $\mathrm{Cu}_{\mathrm{ads}}$ ou com $\mathrm{Cd}_{\mathrm{ads}}$, mesmo a produção de $\mathrm{H}_{2} \mathrm{O}_{2}$ é inibida pelo bloqueio completo dos sítios ativos da superfície, com a correspondente diminuição das correntes no anel. Já no caso do $\mathrm{Pb}$, a situação é um pouco diferente. A modificação da superfície da Pt pela adsorção dos átomos de $\mathrm{Pb}$ causa a mesma mudança no mecanismo da rro que nos casos anteriores, favorecendo a formação 
de $\mathrm{H}_{2} \mathrm{O}_{2}$. Entretanto, a inibição posterior desta reação não é mais observada. Isto se deve ao fato de ser impossível recobrir todos os sítios da superfície da $\mathrm{Pt}$ com $\mathrm{Pb}_{\mathrm{ads}}$, provavelmente devido à diferença entre os raios atômicos ${ }^{34}$.
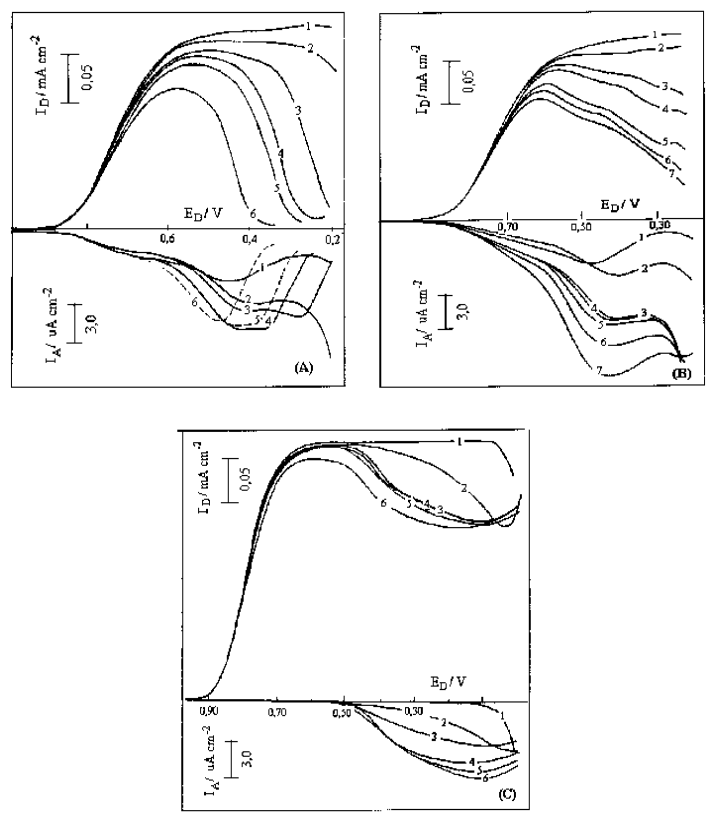

Figura 2. Perfis potenciodinâmicos para a redução de oxigênio no eletrodo rotatório de disco-anel de Pt-Pt em $\mathrm{H}_{2} \mathrm{SO}_{4}$ 0,1 M mais: (A) $\mathrm{CuSO}_{4}$ $O$ (curva 1 ), $10^{-4}$ (curva 2), $3 \times 10^{-4}$ (curva 3 ), $7 \times 10^{-4}$ (curva 4 ), $5 \times 10^{-3}$ (curva 5) e $3 \times 10^{-3} M$ (curva 6); (B) $\mathrm{CdSO}_{4} 0$ (curva 1), $10^{-5}$ (curva 2), $5 \times 10^{-5}$ (curva 3$), 10^{-4}$ (curva 4$), 10^{-3}$ (curva 5) e $5 \times 10^{-3} M$ (curva 6); (C) $\mathrm{Pb}\left(\mathrm{NO}_{3}\right)_{2} \mathrm{O}$ (curva 1), $1 \times 10^{-5}$ (curva 2), $2 \times 10^{-5}$ (curva 3 ), $1 \times 10^{-4}$ (curva 4), $5 \times 10^{-4}$ (curva 5) e $5 \times 10^{-5} \mathrm{M}$ (curva 6), $v=30 \mathrm{mV} \mathrm{s}^{-1}, \omega=1400 \mathrm{rpm}$.

\section{Influência da interação substrato-adsorbato na DRS.}

A deposição em regime de subtensão da prata (DRS Ag) sobre eletrodos de platina policristalina mostra detalhes diferenciados no mecanismo de deposição e continua sendo tema de muita controvérsia na literatura. A principal característica, observada em experimentos voltamétricos com o eletrodo estacionário, são cargas de dissolução maiores do que o esperado para uma monocamada completa, considerando uma transferência de um elétron por ad-átomo e por sítio $\left(210 \mu \mathrm{C} \mathrm{cm}^{-2}\right)$. Além disto, para altos recobrimentos com $\mathrm{Ag}$ (mais do que uma monocamada), têm sido observado o reaparecimento de hidrogênio adsorvido na superfície do substrato. Estes fenômenos têm sido associados com a penetração dos ad-átomos de $\mathrm{Ag}$ para dentro da fase de $\mathrm{Pt}$, formando uma liga intermetálica ${ }^{35}$ com o substrato. Outros estudos apontam para um rearranjo superficial seguido por uma nucleação tridimensional de $\mathrm{Ag}^{36}$.

Com o objetivo de avançar na interpretação deste mecanismo, foi desenvolvida neste laboratório ${ }^{37}$ uma nova metodologia para separar as contribuições da oxidação superficial de Pt e da dissolução da monocamada de Ag, depositada em subtensão. A Figura 3 ilustra a metodologia proposta para separar a densidade de carga de oxidação de $\mathrm{Pt}$ da contribuição relacionada à dissolução da monocamada de $\mathrm{Ag}$. Os experimentos voltamétricos foram feitos com o eletrodo de Pt policristalina em $0,5 \mathrm{M}$ de $\mathrm{H}_{2} \mathrm{SO}_{4}$, e com a adição de $5 \times 10^{-6} \mathrm{M}$ de $\mathrm{AgNO}_{3}$ ao eletrólito e a $0,5 \mathrm{~V} \mathrm{~s}^{-1}$. O branco (linha pontilhada) foi obtido com o eletrólito, sem a presença de $\mathrm{Ag}^{+}$. A densidade de carga anódica total devido à oxidação superficial da Pt ( q $\left._{\mathrm{Pt}-\mathrm{Ox}}\right)$ foi então medida, no branco, entre 0,8 e $1,5 \mathrm{~V}$ como sendo $445 \mu \mathrm{C} \mathrm{cm}^{-2}$. Este valor é bastante próximo daquele medido para a redução de $\mathrm{PtO}$, na mesma solução, entre 1,4 e 0,35 V na varredura catódica (ou seja, qPto-Red $=424$ $\mu \mathrm{C} \mathrm{cm}^{-2}$ ). O outro voltamograma (Fig. 3, linha cheia) foi obtido após a adição de $5 \times 10^{-6} \mathrm{M}$ de $\mathrm{Ag}^{+}$ao eletrólito. A deposição de Ag foi conduzida a $0,7 \mathrm{~V}$ durante $600 \mathrm{~s}$ seguido de uma varredura de potenciais até $0,05 \mathrm{~V}$ e depois pelo ciclo total. A densidade de carga total foi então calculada como antes na região de potenciais entre 0,8 e $1,5 \mathrm{~V}$. O valor encontrado $\left(\mathrm{q}_{\mathrm{Ag} / \mathrm{PtOx}} \equiv \mathrm{q}_{\mathrm{T}-\mathrm{Ox}}\right)$ foi de 641

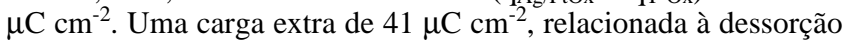
de $\mathrm{H}$ ( $\mathrm{q}_{\mathrm{H}-\mathrm{Ox}}$ ), foi também medida entre 0,05 e 0,5 V. Entretanto, registrando-se o $2^{\mathrm{o}}$ ciclo voltamétrico, após a redissolução da monocamada de prata, obtêm-se um perfil catódico muito próximo ao do branco, com a carga de redução de $\mathrm{PtO}$ de $424 \mathrm{mC} / \mathrm{cm}^{-2}$. Desta maneira, a densidade de carga anódica total deve ser o resultado dos dois processos discutidos acima.

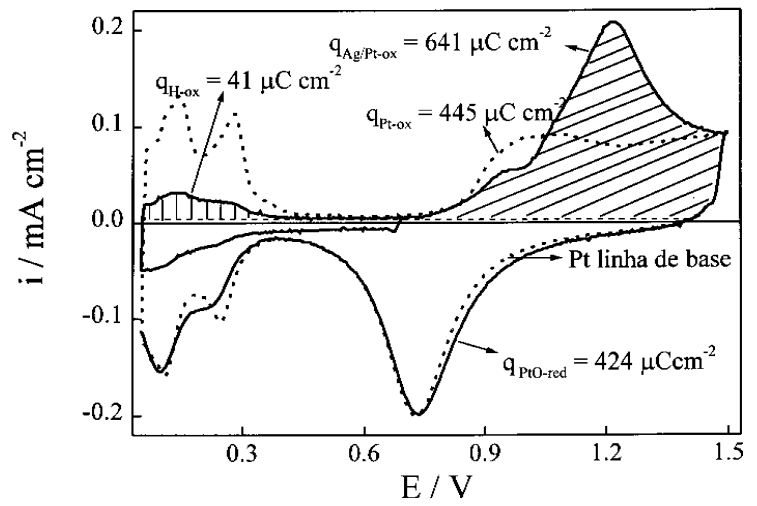

Figura 3. Voltamogramas cíclicos de estado estacionário para a Pt em meio de $\mathrm{H}_{2} \mathrm{SO}_{4}$ 0,5 $\mathrm{M}$ e de primeiro ciclo após o acréscimo de

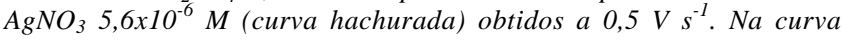
relativa à Ag, foi empregado um tempo de deposição de 600 s no potencial de 0,7 V, para a deposição da monocamada completa.

A partir destas conclusões, a determinação da densidade de carga de oxidação da $\mathrm{Ag}$ requer o registro da segunda varredura catódica. A carga de redução encontrada para o PtO (qPto-Red $=$ $\left.424 \mu \mathrm{C} \mathrm{cm}^{-2}\right)^{37}$ foi então subtraída do valor encontrado para a oxidação total $\left(\mathrm{q}_{\mathrm{T}-\mathrm{Ox}}=641 \mu \mathrm{C} \mathrm{\textrm {cm } ^ { - 2 }}\right)$. O resultado $\left(\mathrm{q}_{\mathrm{Ag}-\mathrm{Ox}}=217\right.$ $\mu \mathrm{C} \mathrm{cm}{ }^{-2}$ ) torna-se próximo àquele esperado para a oxidação de uma monocamada completa de Ag sobre Pt. A adsorção de hidrogênio residual deve-se a um desajuste entre os raios atômicos de Ag e Pt, que resulta em um recobrimento máximo de 0,9. Esses resultados anteriores foram totalmente confirmados com experimentos de coleção obtidos com o eletrodo rotatório de disco-anel. Os experimentos foram conduzidos a $2000 \mathrm{rpm}$ e a deposição de $\mathrm{Ag}$ foi conduzida no disco a $0,7 \mathrm{~V}$ em 0,5 M $\mathrm{H}_{2} \mathrm{SO}_{4}+3 \times 10^{-6} \mathrm{M}$ de $\mathrm{AgNO}_{3}$ nos seguintes tempos de deposição: $30,60,180$ e 300 s. O anel foi recoberto com Ag depositada a $0,2 \mathrm{~V}$ durante $300 \mathrm{~s}$. A densidade de carga para a dissolução de $\mathrm{Ag}$ no disco $\left(\mathrm{q}_{\mathrm{Ag}-\mathrm{Ox}}\right)$ foi calculada a partir da área sob as curvas de variação de corrente do anel, e pelo fator de coleção. $\mathrm{O}$ valor encontrado ${ }^{37}\left(213 \mu \mathrm{C} \mathrm{cm}^{-2}\right)$ está muito próximo ao encontrado com os experimentos voltamétricos. Como o valor encontrado com o eletrodo de disco anel rotatório é livre da influência da oxidação superficial, a similaridade entre as densidades de carga calculadas com os dois métodos confirmam a validade da metodologia empregada neste trabalho.

A DRS de $\mathrm{Cu}$ e Ag sobre ouro policristalino também apresenta características determinadas pela interação substratoadsorbato $^{38}$. As respostas voltamétricas do eletrodo de Au policristalino em eletrólitos desaerados de: (a) $\mathrm{H}_{2} \mathrm{SO}_{4} 0,5 \mathrm{M}+$ $\mathrm{CuSO}_{4} 5 \times 10^{-5} \mathrm{M}$ a $0,5 \mathrm{~V} \mathrm{~s}^{-1}$ e com o potencial de deposição de $0,17 \mathrm{~V}$ mantido por $300 \mathrm{~s}$ e (b) $\mathrm{AgNO}_{3} 5,6 \times 10^{-5} \mathrm{M}+$ $\mathrm{H}_{2} \mathrm{SO}_{4} 0,5 \mathrm{M}$ a $0,5 \mathrm{~V} \mathrm{~s}^{-1}$, após manutenção durante $300 \mathrm{~s}$ do potencial de $0,5 \mathrm{~V}$, são apresentadas na Figura 4, juntamente 
com o respectivo perfil da solução do branco para o eletrodo estacionário (linha cheia). No caso da DRS $\mathrm{Cu}$, é bastante simples obter as cargas de dissolução dos ad-átomos. Neste caso, a carga máxima encontrada para a monocamada foi de $405 \mu \mathrm{C} \mathrm{cm}$, o que corresponde à formação de uma monocamada completa, com a transferência de dois elétrons pôr ad-átomo. Já no caso da DRS $\mathrm{Ag}$, o cálculo das cargas de dessorção da monocamada de $\mathrm{Ag}$ depositada torna-se mais complexo, devido à superposição dos picos voltamétricos relativos à oxidação da $\mathrm{Ag}$ e da superfície da Pt. Assim, a utilização do eletrodo rotatório de disco-anel é imprescindível. Aqui, o eletrodo de anel foi polarizado em $0,2 \mathrm{~V}$ durante 5 minutos em $\mathrm{H}_{2} \mathrm{SO}_{4} 0,5 \mathrm{M}+\mathrm{AgNO}_{3} 5,6 \times 10^{-5} \mathrm{M}$, de maneira a promover a deposição maciça de $\mathrm{Ag}$. $\mathrm{O}$ sistema rotatório foi mantido a $2000 \mathrm{rpm}$ durante todo o experimento. Após a estabilização da corrente Nernstiana do anel, o disco foi polarizado em $0,6 \mathrm{~V}$ por $600 \mathrm{~s}$ para se atingir o recobrimento máximo com $\mathrm{Ag}_{\text {ads. }}$ A seguir, o potencial do disco foi varrido na direção anódica, a $0,1 \mathrm{~V} \mathrm{~s}^{-1}$, de forma a dissolver a camada de prata depositada. As respostas corrente-potencial obtidas para as perturbações do disco e anel são apresentadas na Figura 5. A carga calculada com esta metodologia para a monocamada completa de Ag foi de $115 \mu \mathrm{C} \mathrm{cm}^{-2}$, o que indica a ocupação de apenas metade dos sítios ativos da superfície do eletrodo, numa transferência de um elétron para cada sítio.

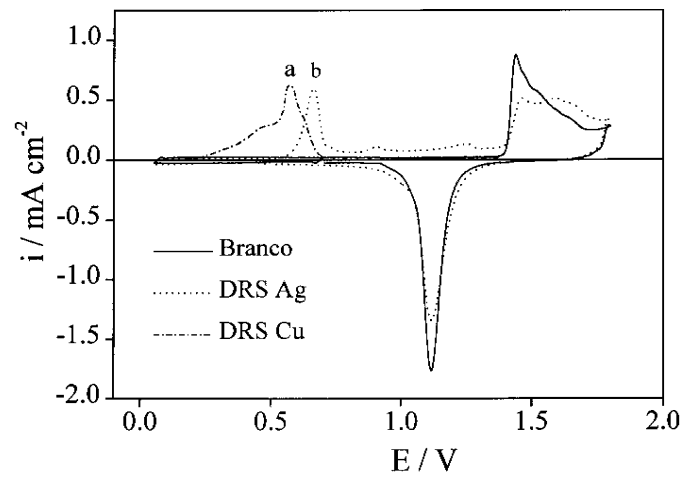

Figura 4. Respostas voltamétricas de primeiro ciclo do eletrodo de Au policristalino em: $\mathrm{H}_{2} \mathrm{SO}_{4} 0,5 \mathrm{M}+\mathrm{CuSO}_{4} 5 \times 10^{-5} \mathrm{MaO} 0,5 \mathrm{Vs}^{-1}$ (a) e $\mathrm{H}_{2} \mathrm{SO}_{4} 0,5 \mathrm{M}+\mathrm{AgNO}_{3} 5,6 \times 10^{-5} \mathrm{Ma} 0,5 \mathrm{~V} \mathrm{~s}^{-1}$ (b). Os potenciais de deposição utilizados foram de 0,17 V (a) e 0,5 V(b), aplicados durante $300 \mathrm{~s}$ para assegurar a deposição da monocamada completa.

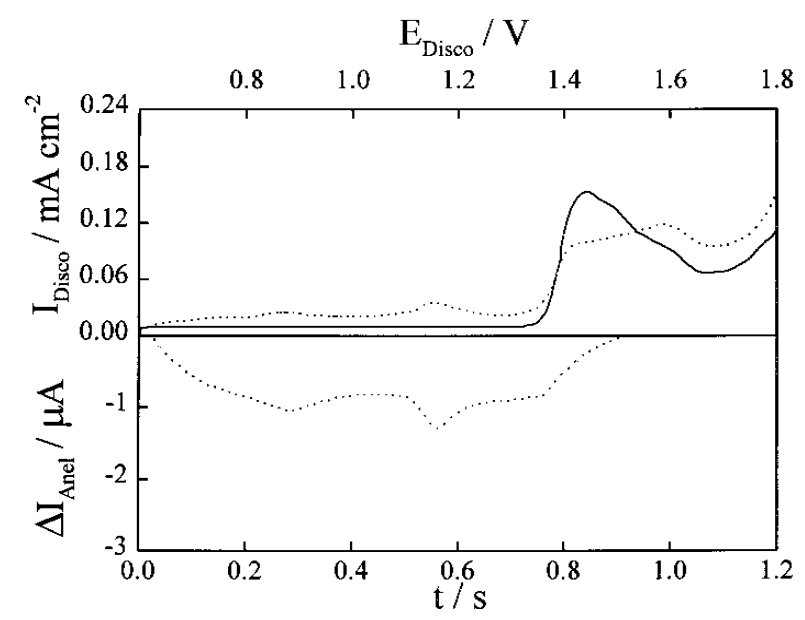

Figura 5. Perfis potenciodinâmicos para o eletrodo rotatório de disco-anel de $\mathrm{Au}$-Pt em meio de $\mathrm{H}_{2} \mathrm{SO}_{4}$ 0,5 $\mathrm{M}$ (linha cheia) + $\mathrm{AgNO}_{3}$ $5,6 \times 10^{-5} M$ (linha pontilhada). O anel foi mantido polarizado em 0,2 $V$ desde 5 minutos antes e durante o experimento com $\omega=2000 \mathrm{rpm}$. $O$ disco foi polarizado em 0,6 V por $600 \mathrm{~s}$ e, a seguir, seu potencial foi varrido a $0,1 \mathrm{~V} \mathrm{~s}^{-1}$ na direção anódica.
Uma comparação entre os resultados obtidos para $\mathrm{Cu}$ e $\mathrm{Ag}$ sobre $\mathrm{Au}$ em meio de ácido sulfúrico permite postular que os átomos de $\mathrm{Cu}$ se depositam de maneira epitaxial, ou seja, seguindo a orientação cristalográfica do substrato, num recobrimento completo dos sítios ativos da superfície. Para a prata, é provável que os ad-átomos se adsorvam em um empacotamento aberto, ocupando somente metade dos sítios ativos disponíveis. Estes resultados obtidos estão de acordo com trabalhos mais recentes que apontam para evidências da adsorção simultânea de espécies bissulfato sobre $\mathrm{Au}$, de maneira muito mais forte que $\mathrm{Ag}^{39}$. Em eletrodos monocristalinos de $\mathrm{Au}$ foi mostrado que os ânions sulfato estão presentes na superfície do Au no intervalo de potenciais da deposição em subtensão de Ag, onde o máximo de recobrimento com $\mathrm{Ag}_{\text {ads }}$ é da ordem de $44 \%$ de uma monocamada ${ }^{40}$. Assim, o baixo recobrimento encontrado para a monocamada de Ag pode estar relacionado com a adsorção simultânea de ânions, que bloqueiam os sítios ativos da superfície do $\mathrm{Au}$.

\section{Transferência parcial de carga na deposição em regime de subtensão.}

A deposição em subtensão de cádmio sobre Pt tem sido estudada principalmente devido às características peculiares deste sistema ${ }^{3,33}$. Em primeiro lugar, a sobreposição dos picos de dessorção das submonocamadas de cádmio e hidrogênio adsorvidos torna difícil a avaliação das cargas relativas a cada um dos processos. Assim, este é um dos casos, como a prata, em que a utilização de outras técnicas de análise como por exemplo o eletrodo de disco-anel rotatório, torna-se determinante. Em segundo lugar, trabalhos prévios mostram que a valência do $\mathrm{Cd}_{\mathrm{ads}}$ não é zero, como para os demais ad-átomos, mas em torno de $0,5^{3}$, uma característica pouco usual. Finalmente, o potencial de deposição reversível para o par $\mathrm{Cd}^{2+} / \mathrm{Cd}$ $\left(-0,403 \mathrm{~V}^{3}\right)$ é muito afastado da região de deposição em subtensão, não exercendo qualquer influência neste estudo.

Com o objetivo de aprofundar os conhecimentos da DRS Cd sobre $\mathrm{Pt}$ e $\mathrm{Au}$ policristalinos em meio ácido ${ }^{41}$, foram feitos experimentos voltamétricos, tanto com o eletrodo estacionário como no rotatório, em meio de $\mathrm{H}_{2} \mathrm{SO}_{4} 0,1 \mathrm{M}+\mathrm{CdSO}_{4} 5 \times 10^{-5} \mathrm{M}$. A Fig. 6 mostra as respostas voltamétrica da $\mathrm{Pt}$ (a) e do $\mathrm{Au}$ (b) nos diversos tempos de deposição. Os experimentos foram conduzidos a $0,2 \mathrm{~V} \mathrm{~s}^{-1}$, com o potencial de deposição fixado em $0,05 \mathrm{~V}$. A resposta voltamétrica obtida para a redissolução da monocamada sobre $\mathrm{Pt}$, revela que o $\mathrm{Cd}_{\mathrm{ads}}$ inibe a adsorção do hidrogênio, principalmente daquele fracamente adsorvido. Ao se representar a relação entre as cargas de $\mathrm{Cd}_{\mathrm{ads}}$ e de $\mathrm{H}_{\mathrm{ads}}$, obtém-se, para baixos recobrimentos com $\mathrm{Cd}$, uma reta cujo coeficiente angular fornece o valor de 1,5 elétrons transferindo-se para cada sítio ativo da superfície $^{41}$, já que cada átomo de $\mathrm{Cd}$ desloca um átomo de $\mathrm{H}$ da superfície (o que pode ser suposto devido à similaridade entre os raios atômicos do $\mathrm{Cd}, 1,54 \AA$ e da Pt, 1,39 ̊̊). Este dado evidencia a valência de eletrossorção de 0,5 , valor próximo àqueles já reportados anteriormente para os ad-átomos de $\mathrm{Cd}^{42}$. Além disto, o valor da carga de dessorção da monocamada completa (isto é, quando não se observa mais hidrogênio adsorvido) é $285 \mu \mathrm{C} \mathrm{cm}^{-2}$, que corresponde a $85 \%$ da monocamada de $\mathrm{Cd}^{0,5+}$ adsorvido (considerando-se $420 \mu \mathrm{C} \mathrm{cm}$ para a formação de uma monocamada completa, com a transferência de 2 elétrons).

Para validar os resultados de voltametria cíclica utilizou-se a técnica do eletrodo de disco-anel rotatório, conservando-se as mesmas condições experimentais utilizadas com o eletrodo estacionário e descritas acima. Sendo assim, as cargas relativas à monocamada de $\mathrm{Cd}_{\mathrm{ads}}$ podem ser calculadas pela variação de corrente do anel. A resposta do anel evidenciou três picos distintos, na mesma região de potenciais daqueles observados na resposta de corrente do disco, com uma densidade de carga total de $74,1 \mu \mathrm{C} \mathrm{cm}^{-2}$. Quando corrigida pelo fator de coleção do sistema rotatório, 0,195 , este valor pode ser transposto para o disco como sendo $380 \mu \mathrm{C} \mathrm{cm}$. Este valor não reflete a 

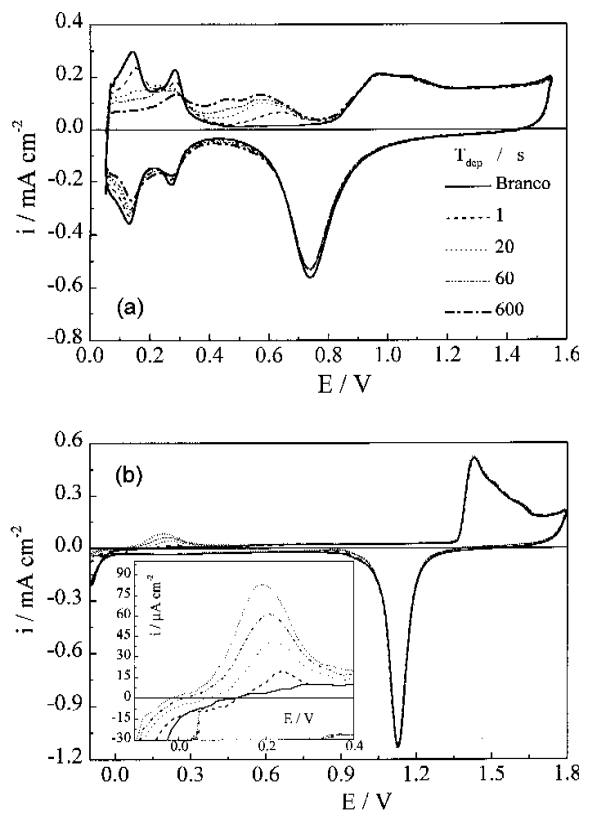

Figura 6. Voltamogramas cíclicos de estado estacionário para a Pt (a) e o Au (b) em meio de $\mathrm{H}_{2} \mathrm{SO}_{4}$ 0,1 M (linhas cheias) e de primeiro ciclo após a adição de $\mathrm{CdSO}_{4} 5 \times 10^{-5} \mathrm{M}$ ao eletrólito, a 0,2 $\mathrm{V} \mathrm{s}^{-1}$. A legenda da Figura 6 a mostra os tempos de deposição utilizados em ambos experimentos, no potencial de deposição de 0,05 V. O inserto da Figura $6 b$ mostra ampliada a região de deposição em subtensão do $\mathrm{Cd}$.

valência de eletrossorção do $\mathrm{Cd}$ no disco, desde que no anel a deposição ocorre para formar $\operatorname{Cd}(0)$. Desta maneira, a relação observada entre as densidades de carga no disco, calculadas pela variação de corrente do anel e diretamente do voltamograma do disco, para o recobrimento máximo com $\mathrm{Cd}_{\mathrm{ads}}$, permite obter a valência de eletrossorção de Cd sobre Pt. Esta relação apresenta o valor de 0,5 , exatamente como observado nos experimentos voltamétricos com o eletrodo estacionário.

A DRS Cd sobre Au tem, como principal característica, o pequeno valor de carga associada à redissolução da monocamada completa. Neste trabalho ${ }^{41}$, executado nas mesmas condições descritas anteriormente para $\mathrm{Pt}$, tanto nos experimentos voltamétricos com o eletrodo estacionário como com o eletrodo rotatório, a carga máxima obtida para a monocamada completa de $\mathrm{Cd}_{\text {ads }}$ foi de 41

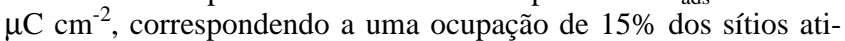
vos. Para a obtenção deste valor de recobrimento, foi assumido uma transferência de 1,5 elétrons, de maneira análoga àquela observada para a Pt. Para se justificar este baixo recobrimento encontrado, foi inicialmente proposta a participação da adsorção dos ânions sulfato neste intervalo de potenciais (mais forte sobre $\mathrm{Au}$ do que sobre $\mathrm{Pt}$ ), bloqueando os sítios ativos necessários para a adsorção do $\mathrm{Cd}$. Entretanto, o mesmo recobrimento máximo foi encontrado em experimentos utilizando-se $\mathrm{HClO}_{4}$ como eletrólito de suporte. Assim, concluiu-se que o recobrimento máximo da superfície do Au de apenas $15 \%$ se deve às características intrínsecas da interação entre $\mathrm{Cd}$ e Au. Esta interação pode ser revelado pelas isotermas de adsorção deste sistema.

Influência de diferentes estados de oxidação do íon metálico na solução em sua deposição em regime de subtensão.

A deposição em regime de subtensão de Sn (a partir dos íons metálicos $\mathrm{Sn}(\mathrm{IV})$ e $\mathrm{Sn}(\mathrm{II})$ ) sobre $\mathrm{Pt}$, em meio ácido, tem sido estudada a muito tempo devido à sua utilização, de forma bastante intensa, em estudos de eletrocatálise de pequenas moléculas orgânicas como o metanol ${ }^{43}$, ácido fórmico ${ }^{44}$ e monóxido de carbono $^{44}$. O efeito catalítico do estanho na velocidade das reações citadas, deve-se, principalmente, à formação de um complexo
(O-Sn-Pt), sobre a superfície da $\mathrm{Pt}$, na região de potenciais onde ocorre a oxidação das pequenas moléculas orgânicas.

Dentro deste contexto, estudou-se a DRS de Sn sobre Pt e Au, a partir de seus sais di e tetravalentes em soluções de $\mathrm{H}_{2} \mathrm{SO}_{4} 0,5$ $\mathrm{M}$, por meio de voltametria cíclica com o eletrodo estacionário e com o eletrodo rotatório de disco-anel ${ }^{45}$. A Figura 7 mostra a resposta voltamétrica do eletrodo estacionário de $\mathrm{Pt}$ em um eletrólito de $\mathrm{H}_{2} \mathrm{SO}_{4} 0,5 \mathrm{M}$ (curvas tracejadas) e com o acréscimo de: (a) $\mathrm{Sn}\left(\mathrm{SO}_{4}\right)_{2}$ e (b) $\mathrm{SnSO}_{4} 5 \times 10^{-5} \mathrm{M}$, a $0,1 \mathrm{~V} \mathrm{~s}^{-1}$, com uma monocamada de $\mathrm{Sn}_{\text {ads }}$ obtida polarizando-se o eletrodo em $0,4 \mathrm{~V}$ por $300 \mathrm{~s}$. A janela de potenciais foi estendida para limites mais negativos visando-se observar as correntes de desprendimento de hidrogênio. A carga máxima, obtida para a redissolução da monocamada depositada a partir do Sn(IV) em solução, foi de $340 \mu \mathrm{C}$ $\mathrm{cm}^{-2}$, com ainda $105 \mu \mathrm{C} \mathrm{cm}$ (meia monocamada) de hidrogênio adsorvido. $\mathrm{O}$ valor da carga máxima de dessorção da monocamada de $\mathrm{Sn}_{\text {ads }}$ foi totalmente confirmada pela técnica de coleção do eletrodo rotatório ${ }^{45}$. Isto significa que o estanho se deposita (a partir do Sn(IV) em solução) em um empacotamento aberto, com espaço para a deposição de meia monocamada de hidrogênio. Este valor de carga máxima da monocamada corresponde à ocupação de aproximadamente $40 \%$ dos sítios ativos da superfície. Esta característica está relacionada com a diferença entre os raios atômicos do ad-átomo e do substrato, $\mathrm{r}_{\mathrm{Sn}} / \mathrm{r}_{\mathrm{Pt}}=1,4^{46}$, indicando que cada $\mathrm{Sn}$ necessita de dois sítios ativos da superfície, numa deposição similar à do $\mathrm{Pb}$, descrita anteriormente. Além disto, é possível observar, ainda na Figura 7a, que a reação de desprendimento de hidrogênio não é inibida com a deposição da monocamada de $\mathrm{Sn}_{\mathrm{ads}}$, observação esta que concorda com a proposição de um empacotamento aberto. Por outro lado, a dessorção de uma monocamada de $\mathrm{Sn}_{\text {ads }}$ obtida pela deposição a partir do $\mathrm{Sn}$ (II), forneceu uma carga de $210 \mu \mathrm{C} \mathrm{cm}^{-2}$. Este valor significa que cada sítio ativo da superfície eletródica recebeu um elétron. Como cada íon Sn (II) recebe dois elétrons para se descarregar e ocupa dois sítios (devido à diferença de raios atômicos, discutido acima), aquele valor de carga máxima da monocamada sugere que todos os sítios da superfície são ocupados por $\mathrm{Sn}_{\mathrm{ads}}$. Assim, neste caso, o empacotamento dos ad-átomos parece ser cerrado, sem espaço para a adsorção de hidrogênio. Isto está representado na Figura $7 \mathrm{~b}$, onde se observa a total inibição, tanto da adsorção quanto da evolução de hidrogênio. Com estes experimentos, mostrou-se que a forma de deposição do Sn sobre Pt policristalina depende, de maneira acentuada, da valência do íon em solução. Estes resultados concordam com aqueles obtidos anteriormente por Szabó ${ }^{47}$, que propôs uma redução parcial do Sn(IV) para Sn(II), seguida da adsorção deste íon na superfície, finalizando com a redução total do $\mathrm{Sn}(\mathrm{II})_{\text {ads }}$ para $\mathrm{Sn}_{\text {ads }}$. Com a adsorção do íon bivalente, a repulsão lateral é muito grande, o que justifica o empacotamento aberto da monocamada.

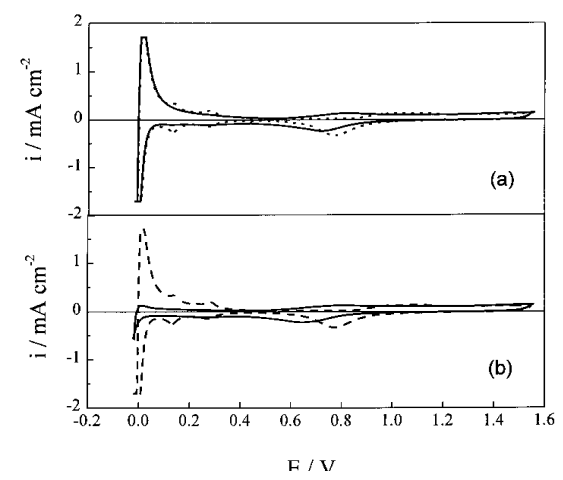

Figura 7. Voltamogramas cíclicos de estado estacionário para Pt, obtidos em uma solução de $\mathrm{H}_{2} \mathrm{SO}_{4}$ 0,5 M (linha tracejada) e de primeiro ciclo após a adição de: $\mathrm{Sn}\left(\mathrm{SO}_{4}\right)_{2} 5 \times 10^{-5}$ (a) ou $\mathrm{SnSO}_{4} 5 \times 10^{-4} \mathrm{M}(\mathrm{b})$ (linhas contínuas) a $0,1 \mathrm{~V} \mathrm{~s}^{-1}$. Potencial de deposição utilizado de $0,4 \mathrm{~V}$ durante $300 \mathrm{~s}$. 
Influência da deposição simultânea de ânions na deposição em subtensão de $\mathbf{Z n}$

Os estágios iniciais da eletrodeposição de Zn em diferentes substratos e eletrólitos têm sido estudados extensivamente ${ }^{48,49}$. Entretanto, a maior ênfase nestes estudos é dada para a variação dos potenciais e das larguras dos picos em subtensão, que está relacionada com a energia do sistema, mas não com seu mecanismo ou modelo.

Desta maneira, neste trabalho ${ }^{50}$ mostrou-se resultados relativos às cargas das (sub)monocamadas obtidas e verificou-se seu efeito na adsorção e desprendimento de hidrogênio, reação muito conhecida e que, aqui, foi utilizada como reação de prova para analisar o grau de recobrimento obtido com ad-átomos de $\mathrm{Zn}$.

Na Figura 8 são mostradas as primeiras varreduras de voltamogramas cíclicos sobre Pt, obtidas para as soluções de : (a) $\mathrm{HClO}_{4} 0,5 \mathrm{M}+\mathrm{ZnSO}_{4} 5 \times 10^{-5} \mathrm{M}$ (linha pontilhada), $\mathrm{H}_{2} \mathrm{SO}_{4}$ $0,5 \mathrm{M}+\mathrm{ZnSO}_{4} 5 \times 10^{-5} \mathrm{M}$ (linha tracejada) e $\mathrm{HF} 0,5 \mathrm{M}+$ $\mathrm{ZnSO}_{4} 5 \times 10^{-5} \mathrm{M}$ (linha cheia), obtidos a $0,2 \mathrm{~V} \mathrm{~s}^{-1}$ e (b) $\mathrm{KOH}$ $0,5 \mathrm{M}+\mathrm{ZnSO}_{4} 5 \times 10^{-5} \mathrm{M}$ obtidos a $0,1 \mathrm{~V} \mathrm{~s}^{-1}$ com tempos de deposição da monocamada correspondentes àqueles necessários para a obtenção de um recobrimento máximo com $\mathrm{Zn}_{\mathrm{ads}}$ (600 s) no potencial de 0,05 V. Finalmente, a Figura 9 corresponde aos experimentos com o eletrodo rotatório a $2000 \mathrm{rpm}$ em HF $0,5 \mathrm{M}+\mathrm{ZnSO}_{4} 10^{-5} \mathrm{M}$, sobre $\mathrm{Pt}$, a $0,2 \mathrm{~V} / \mathrm{s}$, com o anel polarizado em $-0,5 \mathrm{~V}$. Pode-se observar uma profunda dependência do perfil voltamétrico com a natureza do eletrólito de suporte. Os valores máximos de cargas de redissolução da monocamada de $\mathrm{Zn}$, obtidos em cada experimento tanto sobre Pt quanto sobre Au, são apresentados na Tabela 1.

Outro critério que foi utilizado para a interpretação das cargas apresentadas na Tabela 1 relaciona-se com a presença ou não da adsorção/desprendimento de hidrogênio. Uma associação das cargas da Tabela 1 e da presença (ou ausência) de correntes devido à reação de desprendimento de hidrogênio permite postular que: (a) sobre $\mathrm{Pt}$, em meio de $\mathrm{H}_{2} \mathrm{SO}_{4}$ o recobrimento máximo da superfície com $\mathrm{Zn}_{\text {ads }}$ é de $50 \%$. Isto é justificado pela carga máxima de dessorção da monocamada obtida (210 $\mu \mathrm{C} \mathrm{cm}^{-2}$ ) e pela presença de $\mathrm{H}_{\mathrm{ads}}$, assim como pela mínima interferência no desprendimento de hidrogênio. Foi proposto ${ }^{50}$ que a adsorção do íon bissulfato, sobre o ad-átomo de Zn, bloqueia o sítio ativo vizinho, com uma ligação entre o $\mathrm{H}$ do bissulfato e a superfície, impedindo a sua ocupação por outro ad-átomo de Zn. Nos potenciais negativos necessários para a adsorção/desprendimento do hidrogênio, a ligação entre o $\mathrm{H}$ e o $\mathrm{O}$ do íon bissulfato é rompida, gerando metade da monocamada de $\mathrm{H}_{\text {ads. }}$ Comportamento muito similar foi observado em meio de $\mathrm{HClO}_{4}$, novamente devido às interações entre o $\mathrm{H}$ e o $\mathrm{O}$ do

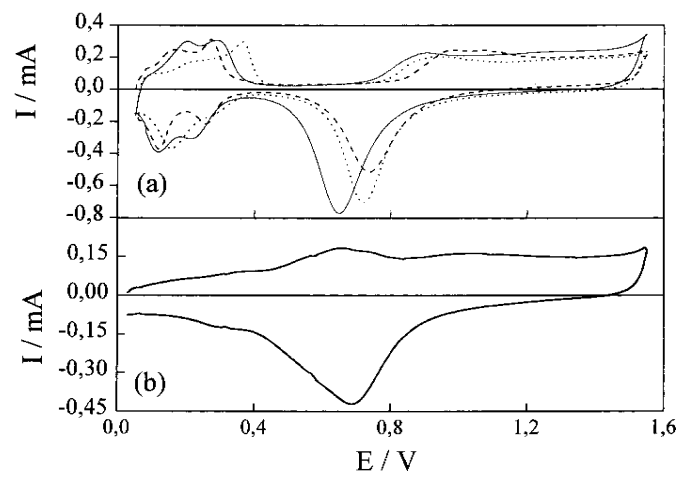

Figura 8: Perfis voltamétricos de primeiro ciclo para o eletrodo de Pt em meio de (a) $\mathrm{HClO}_{4}$ 0,5 $\mathrm{M}+\mathrm{ZnSO}_{4}$ 5x10-5 M (linha pontilhada), $\mathrm{H}_{2} \mathrm{SO}_{4}$ 0,5 $\mathrm{M}+\mathrm{ZnSO}_{4} 5 \times 10-5 \mathrm{M}$ (linha tracejada) e $\mathrm{HF} 0,5 \mathrm{M}+\mathrm{ZnSO}_{4}$

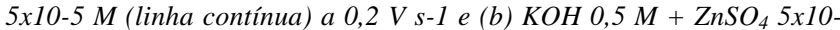
$5 \mathrm{M}$ obtido a 0,1 V s-1. Potencial de deposição de 0,05 V, mantido durante 600 s para assegurar o recobrimento máximo da monocamada.

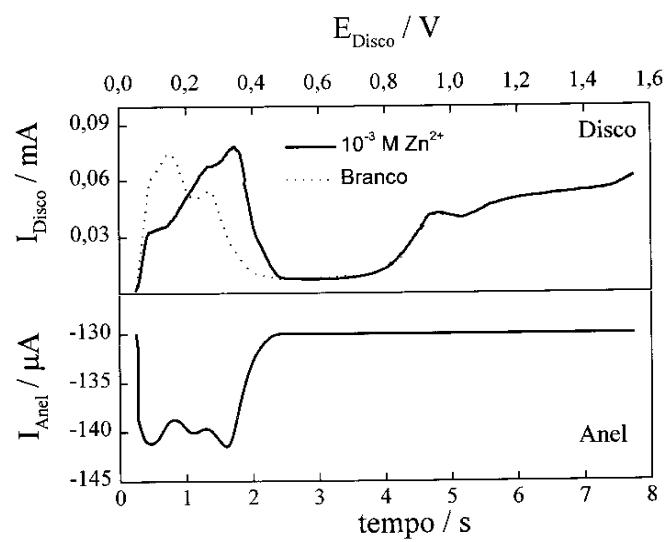

Figura 9. Perfis potenciodinâmicos para o eletrodo rotatório de disco-anel de Pt-Pt em meio de $\mathrm{HF}$ 0,5 M (linha tracejada) $+\mathrm{ZnSO}_{4} 10^{-}$ ${ }^{5} \mathrm{M}$ (linha cheia). $O$ anel foi mantido polarizado em $-0,5 \mathrm{~V}$ desde 5 minutos antes e durante o experimento com $w=2000 \mathrm{rpm}$. $O$ disco foi polarizado em 0,05 V por $600 \mathrm{~s}$ e, a seguir, seu potencial foi varrido a $0,2 \mathrm{~V} \mathrm{~s}^{-1}$ na direção anódica.

Tabela 1. Valores de cargas de redissolução e efeito sobre a reação de adsorção/desprendimento de hidrogênio, nos diferentes meios para a monocamada de $\mathrm{Zn}$ depositada em subtensão sobre Pt e Au.

\begin{tabular}{|c|c|c|c|c|c|}
\hline \multirow[t]{2}{*}{ Eletrólito } & \multirow[t]{2}{*}[\mathrm{Zn}]{$/ \mathrm{M}$} & \multicolumn{2}{|c|}{ 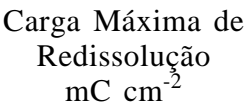 } & \multicolumn{2}{|c|}{$\begin{array}{l}\text { Inibição } \\
\text { da RDH }\end{array}$} \\
\hline & & $\mathrm{Pt}$ & $\mathrm{Au}$ & $\mathrm{Pt}$ & $\mathrm{Au}$ \\
\hline $0,5 \mathrm{M} \mathrm{HF}$ & $\begin{array}{l}1 \times 10-^{5} \\
1 \times 10-^{4} \\
1 \times 10-^{3}\end{array}$ & $\begin{array}{c}- \\
- \\
360\end{array}$ & $\begin{array}{c}- \\
- \\
200\end{array}$ & $\begin{array}{c}\text { Pouca } \\
- \\
\text { Total }\end{array}$ & $\begin{array}{c}- \\
- \\
\text { Total }\end{array}$ \\
\hline $0,5 \mathrm{M} \mathrm{HClO} 4$ & $\begin{array}{l}1 \times 10-^{5} \\
1 \times 10-^{4} \\
1 \times 10-{ }^{3}\end{array}$ & $\begin{array}{c}210 \\
- \\
230\end{array}$ & $\begin{array}{c}- \\
- \\
200\end{array}$ & $\begin{array}{c}\text { Pouca } \\
- \\
\text { Pouca }\end{array}$ & $\begin{array}{c}- \\
- \\
\text { Total }\end{array}$ \\
\hline $0,5 \mathrm{M} \mathrm{H} 2 \mathrm{SO} 4$ & $\begin{array}{l}1 \times 10-^{5} \\
1 \times 10-^{4} \\
1 \times 10-{ }^{3}\end{array}$ & $\begin{array}{c}225 \\
- \\
-\end{array}$ & - & $\begin{array}{c}\text { Pouca } \\
- \\
-\end{array}$ & $\begin{array}{l}- \\
- \\
-\end{array}$ \\
\hline $0,5 \mathrm{M} \mathrm{KOH}$ & $\begin{array}{l}1 \times 10-^{5} \\
1 \times 10-4 \\
1 \times 10-3\end{array}$ & $\begin{array}{c}216 \\
- \\
-\end{array}$ & $\begin{array}{c}394 \\
- \\
-\end{array}$ & $\begin{array}{c}\text { Total } \\
- \\
-\end{array}$ & $\begin{array}{c}\text { Total } \\
- \\
-\end{array}$ \\
\hline
\end{tabular}

íon perclorato. Com a utilização do HF, foram obtidas cargas voltamétricas maiores, aparentemente em concordância com o discutido acima, pois o íon fluoreto adsorvido não apresenta $\mathrm{H}$ e $\mathrm{O}$ para interagir com a superfície do eletrodo, (b) sobre Pt, em meio de $\mathrm{KOH}$, observou-se uma carga voltamétrica de

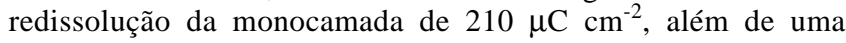
total inibição da adsorção/desprendimento de hidrogênio. Isto sugere um bloqueio total dos sítios ativos da superfície com adátomos de $\mathrm{Zn}$. Entretanto, para justificar o valor da carga observado, é necessário supor a transferência de apenas um elétron para cada íon $\mathrm{Zn}^{2+}$. Para tal, foi postulada a formação de uma espécie $\mathrm{ZnOH}_{\text {ads }}$, estável na superfície do eletrodo, com base em modelos previamente publicados ${ }^{50}$, (c) com o eletrodo de $\mathrm{Au}$, em meio ácido, foi impossível obter qualquer resposta da deposição em subtensão de $\mathrm{Zn}$, no intervalo de potenciais utilizado para a Pt. Entretanto, em meio de HF 0,5 M e com potenciais de adsorção de $-0,5 \mathrm{~V}$, foi possível conseguir cargas equivalentes a uma monocamada de $\mathrm{Zn}_{\text {ads }}$ e uma total inibição da adsorção/desprendimento de hidrogênio Isto foi associado à forte interação entre Au e os íons bissulfato, com o total bloqueio dos sítios ativos da superfície para o $\mathrm{Zn}^{2+}$ e (d) em meio alcalino, sobre Au, observou-se uma carga de $390 \mu \mathrm{C} \mathrm{cm}{ }^{-2}$, 
assim como a total supressão das correntes relacionadas com o desprendimento de hidrogênio. Isto indica a formação de uma monocamada completa de $\mathrm{Zn}_{\text {ads }}$, com a transferência de 2 elétrons por sítio ativo, como era esperado pela relação entre os tamanhos dos átomos (ou seja, $\mathrm{r}_{\mathrm{Pt}}=1,39 \AA \mathrm{e} \mathrm{r}_{\mathrm{Zn}}=1,38 \AA$ ). Este comportamento confirma a profunda influência dos ânions do eletrólito suporte na DRS do Zn.

\section{CONCLUSÕES}

Os estudos da DRS de diversos metais, reportados aqui, mostram que é possível a modificação controlada da superfície de metais eletrocatalisadores (como platina ou ouro) pela deposição de quantidades menores do que uma monocamada de metais inertes (cobre, prata, chumbo, cádmio, zinco, etc.). Devido às propriedades intrínsecas da DRS, estas deposições são sempre randômicas e, assim, alteram a geometria dos sítios ativos, modificando os mecanismos de reações eletródicas e podendo levar aquelas de interesse para o mecanismo desejado.

Entretanto, nos procedimentos experimentais envolvendo processos de eletrodeposição de submonocamadas de metais é necessário levar-se em considerações diversos parâmetros importantes, como por exemplo a presença e a natureza de diferentes ânions, os estados de valência dos metais em solução, a região de potenciais utilizada para a deposição dos ad-átomos, a superfície do substrato, etc.

Além disto, para a interpretação dos resultados obtidos e para a elaboração de modelos de ocupação superficial, é necessário empregar-se técnicas experimentais adequadas, que permitam separar as cargas de dessorção das submonocamadas daquelas inerentes a transformações relacionadas com o substrato, como por exemplo a formação e/ou redução dos óxidos superficiais, a adsorção/dessorção de hidrogênio sobre Pt, etc.. Nesta revisão discutiu-se a utilização da técnica de coleção do eletrodo de disco-anel rotatório, como uma das mais adequadas para garantir esta separação. Mostrou-se que as cargas voltamétricas obtidas com o eletrodo estacionário são, muitas vezes, distorcidas pela ocorrência de processos superficiais, em regiões de potenciais muito próximas daquelas utilizadas nos estudos de DRS. Como uma alternativa mais adequada a estes estudos, mostrouse também a possibilidade de se separar estas contribuições com a utilização da técnica de coleção, do eletrodo rotatório de disco-anel. Nesta, a variação da corrente Nernstiana de deposição maciça do metal no eletrodo de anel, durante a dissolução da monocamada previamente depositada no eletrodo de disco, permite calcular de forma precisa a carga da monocamada dissolvida do eletrodo de disco.

\section{AGRADECIMENTOS}

Os autores desejam agradecer ao CNPq e à FAPESP (processos No. 97/02723-5 e No. 97/2987-3) pelos auxílios financeiros.

\section{REFERÊNCIAS}

1. Panchenkov, G. M.; Lebedev, V. P.; Chemical Kinetics and Catalysis; Leib, G., Trad.; MIR Publishers; Moscou, 1976.

2. Hsueh, K-L.; Chin, D. T.; Srinivasan, S.; J. Electroanal. Chem. 1983, 153, 79.

3. Machado, S. A. S.; Tese de Doutorado, IQSC - USP, São Carlos, 1989.

4. Wroblowa, H. S.; Yen-Chi-Pan; Razumney, G.; J. Electroanal. Chem. 1976, 69, 195.

5. Furuya, N.; Motoo, S.; J. Electroanal. Chem. 1979, 98, 189.

6. Conway, B. E.; Angerstein-Kozlowska, H.; Acc. Chem. Res. 1981, 14, 49.

7. Noel, M.; Chandrasekaran, S.; Basha, C. A.; J. Electroanal. Chem. 1987, 255, 93.
8. Fiçicioglu, F.; Kadirgan, F.; J. Electroanal. Chem. 1993, $346,187$.

9. Hölze, M. H.; Retter, U.; Kolb, D. M.; J. Electroanal. Chem. 1994, 371, 101.

10. Szabó, S.; Int. Reviews in Phys. Chem. 1991, 10, 207.

11. Schultze, J. W.; Koppitz, K.; Electrochim. Acta 1976, $21,337$.

12. Lorenz, W.; Salié, G.; J. Electroanal. Chem. 1977, 80, 1.

13. Swathirajan, S.; Bruckenstein, S.; Electrochim. Acta 1983, 28,865

14. Swathirajan, S.; J. Electroanal. Chem. 1987, 221, 211.

15. Ohkuka, T. e Komori, A.; Electrochim. Acta 1998, 21-22, 3269.

16. Fratesi, F., Roventi, G., Giuliani, G. e Tomachuk, C. R.; J. Appl. Electrochem. 1997, 27, 1088.

17. Gómez, E. e Vallés, E.; J. Electroanal. Chem. 1997, $421,157$.

18. Mills, T. E Willis, G. M.; J. Electrochem. Soc. 1953, $100,452$.

19. Nisbet, A. R. e Bard, A. J.; J. Electroanal. Chem. 1963, 6, 332.

20. Bowles, B. J.; Electrochim. Acta 1970, 15, 589.

21. Andricacos, P. C. e Ross, P. N.; J. Electroanal. Chem. 1984, 167, 301.

22. Chierchie, T.; Mayer, C.; Jüttner, K. e Lorenz, W. J.; J. Electroanal. Chem. 1985, 191, 401.

23. Szabó, S.; J. Electroanal. Chem. 1984, 172, 359.

24. Armand, D. e Clavilier, J.; J. Electroanal. Chem. 1987, 233, 251.

25. Chiechie, T. e Mayer, C.; Electrochim. Acta 1988, 33, 341.

26. Huong, C. N. V. e Gonzalez-Tejera, M. J.; J. Electroanal. Chem. 1988, 244, 249.

27. Dakkouri, A. S.; Batina, N. e Kolb, D. M.; Electrochim. Acta 1993, 38, 2467.

28. Mascaro, L. H.; Machado, S. A. S. e Avaca, L. A.; J. Chem. Soc., Faraday Trans. 1997, 93, 2577.

29. Taguchi, S.; Fukuda, T. e Aramata, A.; J. Electroanal. Chem. 1997, 435, 55.

30. Opekar, F. e Beran, P.; J. Electroanal. Chem. 1976, 69, 1.

31. Albery, W. J. e Bruckenstein, S.; J. Chem. Soc., Faraday Trans. 1966, 62, 1920.

32. Machado, S. A. S.; Tanaka, A. A. e Gonzalez, E. R.; Electrochim. Acta 1991, 36, 1325.

33. Machado, S. A. S.; Tanaka, A. A. e Gonzalez, E. R.; Electrochim. Acta 1992, 37, 2559.

34. Machado, S. A. S.; Tanaka, A. A. e Gonzalez, E. R.; Electrochim. Acta 1994, 39, 2591.

35. Ocón, P.; Herrasti, P.; Palacio, C.; Vela, M. E.; Salvarezza, R. C.; Vázquez, L. e Arvia, A. J.; J. Electroanal. Chem. 1993, 357, 339.

36. Alonzo, D. C. e Scharifker, B. R.; J. Electroanal. Chem. 1989, 274, 167.

37. Mascaro, L. H.; Santos, M. C.; Machado, S. A. S. e Avaca, L. A.; J. Chem. Soc., Faraday Trans. 1997, 93, 3999.

38. Santos, M. C.; Mascaro, L. H. e Machado, S. A. S.; Electrochim. Acta 1998, 43, 2263.

39. Seo, M.; Aomi, M. e Yoshida, K.; Electrochim. Acta 1994, 39, 1039.

40. Mrozek, P.; Sung, Y.; Han, M.; Gamboa-Aldeco, M.; Wieckowski, A.; Chen, C. e Gewirth, A. A.; Electrochim. Acta 1995, 40, 17.

41. Santos, M. C. e Machado, S. A. S.; J. Braz. Chem. Soc. 1998, 9, 211.

42. Vargas, K.; Zelenay, P.; Horány, G.; Wieckowski, A.; J. Electroanal. Chem. 1992, 327, 291.

43. Beden, B.; Kadirgan, F.; Lamy, C. e Leger, J. M.; J. Electroanal. Chem. 1981, 127, 75.

44. Motoo, S. e Watanabe, M.; J. Electroanal. Chem., 1976, $69,429$. 
45. Santos, M. C.; Dissertação de Mestrado, IQSC - USP, São Carlos, 1997.

46. Furuya, N. e Motoo, S.; J. Electroanal. Chem. 1979, 98, 189.

47. Szabó, S.; J. Electroanal. Chem. 1984, 172, 359.

48. Aramata, A.; Terui, S.; Taguchi, S.; Kawaguchi, T. e
Shimazu, K.; Electrochim. Acta 1996, 41, 761.

49. Taguchi, S.; Aramata, A.; Quaiyyum, Md. A. e Enyo, M.; J. Electroanal. Chem. 1994, 374, 275.

50. Mascaro, L. H.; Santos, M. C.; Machado, S. A. S. e Avaca, L. A.; J. Chem. Soc., Faraday Trans. 1997, 93, 3999. 